\title{
GAMBARAN PERAWATAN GIGI TIRUAN DI RUMAH SAKIT GIGI DAN MULUT PRODI PENDIDIKAN DOKTER GIGI FAKULTAS KEDOKTERAN UNSRAT TAHUN 2013-2014
}

\author{
${ }^{1}$ Ni Putu Karuni M. Sari \\ ${ }^{2}$ Ni Wayan Mariati \\ ${ }^{2}$ Vonny N.S Wowor
}

\author{
${ }^{1}$ Kandidat Skripsi Program Studi Pendidikan Dokter Gigi Fakultas Kedokteran \\ ${ }^{2}$ Program Studi Pendidikan Dokter Gigi Universitas Sam Ratulangi Manado \\ E-mail: puput_karuni@yahoo.com
}

\begin{abstract}
Loss of teeth in the long term without replacement would lead to changes in the composition of the teeth which can cause interference with speech and mastication function. As people age, the greater the susceptibility to tooth loss. It will have an impact on the growing need for dentures. This study was conducted to determine the image denture care in Rumah Sakit Gigi Mulut (RSGM) Prodi Pendidikan Dokter Gigi (PSPDG) Fakultas Kedokteran (FK) Unsrat in 2013 - 2014. This type of research is descriptive retrospective approach. The population used was patients who have undergone treatment denture years 2013 - 2014 in the RSGM PSPDG FK Unsrat, the data obtained from the medical records of Prosthodontics. Sampling was done by total sampling method with large samples that met the inclusion criteria as much as 353 samples. The result showed that at 2013 the majority treatment was post crown 40,29\%; followed by full crown 38,13\%; denture bridge $11,57 \%$; partial removable denture 6,47\%; full denture $11,57 \%$; at 2014 the majority treatment was full crown $32,71 \%$; followed by full denture $11,16 \%$; partial removable denture $16,82 \%$; post crown 16,82\%; denture bridge 14,49\%.
\end{abstract}

Keywords: denture treatment, RSGM PSPDG FK Unsrat

\begin{abstract}
Abstrak: Kehilangan gigi dalam jangka waktu yang lama tanpa penggantian akan menyebabkan perubahan susunan gigi yang dapat menyebabkan gangguan pada fungsi bicara maupun pengunyahan. Seiring bertambahnya usia, semakin besar pula kerentanan seseorang untuk kehilangan gigi. Hal itu akan berdampak pada meningkatnya kebutuhan akan gigi tiruan. Penelitian ini dilakukan untuk mengetahui gambaran perawatan gigi tiruan di Rumah Sakit Gigi Mulut (RSGM) Prodi Pendidikan Dokter Gigi (PSPDG) Fakultas Kedokteran (FK) Unsrat tahun 2013 - 2014. Jenis penelitian yaitu penelitian deskriptif dengan pendekatan retrospektif. Populasi penelitian yaitu pasien yang telah menjalani perawatan gigi tiruan tahun 2013 - 2014 di RSGM PSPDG FK Unsrat yang datanya diperoleh dari rekam medik prostodonsia. Pengambilan sampel dilakukan dengan metode total sampling dengan besar sampel yang memenuhi kriteria inklusi sebanyak 353 sampel. Hasil penelitian menubnjukkan bahwa pada tahun 2013 terbanyak perawatan mahkota pasak 40,29\%; diikuti perawatan mahkota penuh $38,13 \%$; gigi tiruan jembatan $11,51 \%$; gigi tiruan sebagian lepasan $6,47 \%$; gigi tiruan penuh 3,60\%. Tahun 2014 perawatan terbanyak perawatan mahkota penuh 32,71\%; diikuti perawatan gigi tiruan penuh 19,16\%; gigi tiruan sebagian lepasan 6,82\%; perawatan mahkota pasak 16,82\%; gigi tiruan jembatan 14,49.
\end{abstract}

Kata kunci: perawatan gigi tiruan, RSGM PSPDG FK Unsrat 
Gigi merupakan salah satu organ tubuh yang memiliki fungsi penting dalam tubuh. Gigi terletak dalam rongga mulut dan berperan dalam proses pengunyahan, membantu fungsi bicara serta menunjang penampilan atau memiliki fungsi estetika. Kerusakan pada gigi dapat menyebabkan terjadinya gangguan pada beberapa fungsi di atas, demikian halnya dengan kehilangan gigi. ${ }^{1,2}$

Kehilangan gigi dapat disebabkan oleh beberapa faktor seperti karies yang luas, traumatik, penyakit periodontal (penyakit jaringan pendukung gigi). Berkurangnya jumlah gigi dalam mulut dan tidak dibuatkan penggantinya dapat berdampak pada berkurangnya hingga hilangnya fungsi gigi. Data Riset Kesehatan Dasar tahun 2007 menunjukkan bahwa prevalensi kehilangan gigi pada masyarakat berusia 10-24 tahun sebesar $2,8 \%$, usia $25-44$ tahun sebesar $8,2 \%$, usia 45-64 tahun sebesar $18,2 \%$, dan usia di atas 64 tahun sebesar 14,5\%. Hal ini menggambarkan akan kebutuhan perawatan gigi tiruan. ${ }^{3}$

Menurut Glossary of Prosthodontic gigi tiruan merupakan struktur pendukung atau yang menggantikan satu atau lebih gigi asli yang hilang dengan elemen tiruan dan didukung oleh gigi, mukosa, atau kombinasi gigi mukosa. Perawatan gigi tiruan berperan untuk meningkatkan fungsi pengunyahan, bicara, estetik yang hilang akibat hilangnya gigi. Adanya kebutuhan akan perawatan gigi tiruan pada masyarakat, termasuk masyarakat di kota Manado menyebabkan masyarakat yang mengalami kehilangan gigi akan mencari pelayanan perawatan gigi tiruan. Perawatan gigi tiruan yang dibutuhkan bervariasi, namun secara umum bisa digolongkan atas perawatan gigi tiruan lepasan dan perawatan gigi tiruan cekat. Salah satu institusi yang memberikan pelayanan perawatan gigi tiruan, yakni Rumah Sakit Gigi dan Mulut Program Studi Pendidikan Dokter Gigi Fakultas Kedokteran Universitas Sam Ratulangi atau disingkat RSGM PSPDG FK
Unsrat. $^{4,5}$

Rumah Sakit Gigi dan Mulut PSPDG FK Unsrat merupakan satu-satunya rumah sakit gigi dan mulut di kota Manado dan merupakan salah satu wahana pendidikan profesi mahasiswa PSPDG FK Unsrat. Rumah sakit ini belum lama beroperasi dan salah satu kendala yang ada, yakni pada manajemen perencanaan penyediaan bahan dan obat-obatan yang digunakan dalam proses pembelajaran mahasiswa termasuk bahan yang digunakan dalam perawatan gigi tiruan. Keterbatasan tenaga yang ada serta perencanaan rumah sakit yang masih menjadi satu dengan perencanaan program studi menyebabkan ketersediaan bahan dan obat-obatan di rumah sakit seringkali menjadi masalah.

Untuk melakukan pembenahan dalam perencanaan dibutuhkan banyak data perawatan pasien termasuk data perawatan di bidang prostodonsia. Hasil penelitian yang ada diharapkan dapat memberikan informasi yang bermanfaat bagi RSGM dan PSPDG FK Unsrat dalam melakukan perencanaan.

\section{METODE PENELITIAN}

Desain penelitian yang digunakan dalam penelitian ini adalah desain cross sectional yang bersifat deskriptif dengan pendekatan restrospektif. Penelitian dilaksanakan pada bulan Juni-Juli 2015 di RSGM PSPDG FK UNSRAT Manado, provinsi Sulawesi Utara.

Populasi penelitian ini ialah pasien yang telah menjalani perawatan gigi tahun 2013-2014 di RSGM PSPDG FK Unsrat yang datanya diperoleh dari rekam medik Prostodonsia. Metode pengambilan sampel yang digunakan untuk penelitian ialah total sampling.

\section{HASIL PENELITIAN}

Data dikelompokkan berdasarkan usia, jenis kelamin, dan banyaknya pengguna gigi tiruan, yang kemudian didistribusikan berdasarkan tabel distribusi frekuensi untuk mengetahui gambaran penggunaan gigi tiruan di rumah sakit 
tempat penelitian dilaksanakan. Total pasien yang tercatat melakukan perawatan gigi tiruan di RSGM PSPDG FK UNSRAT Manado pada tahun 2013 sampai tahun 2014 yaitu 353 orang yang diuraikan pada Tabel 1-6

Tabel 1. Distribusi responden gigi tiruan di RSGM berdasarkan jenis kelamin pada tahun 2013

\begin{tabular}{ccc}
\hline Jenis kelamin & (n) & (\%) \\
\hline Perempuan & 85 & 61,15 \\
Laki-laki & 59 & 38,85 \\
Total & 139 & 100 \\
\hline
\end{tabular}

Tabel 2. Distribusi responden gigi tiruan di RSGM berdasarkan jenis kelamin pada tahun 2014

\begin{tabular}{ccc}
\hline $\begin{array}{c}\text { Jenis } \\
\text { kelamin }\end{array}$ & (n) & $(\%)$ \\
\hline Perempuan & 146 & 68,22 \\
Laki-laki & 68 & 31,78 \\
Total & 214 & 100 \\
\hline
\end{tabular}

Tabel 3. Distribusi responden gigi tiruan di RSGM berdasarkan usia pada tahun 2013.

\begin{tabular}{ccc}
\hline Usia & $\begin{array}{c}\text { Jumlah } \\
(\mathrm{n})\end{array}$ & $\begin{array}{c}\text { Persentase } \\
(\%)\end{array}$ \\
\hline$\leq 20$ & 27 & 19,42 \\
$21-30$ & 67 & 48,20 \\
$31-40$ & 22 & 15,83 \\
$41-50$ & 8 & 5,76 \\
$51-60$ & 9 & 6,47 \\
$>60$ & 6 & 4,32 \\
Total & 139 & 100 \\
\hline
\end{tabular}

Tabel 4. Distribusi responden gigi tiruan di RSGM berdasarkan usia pada tahun 2014.

\begin{tabular}{ccc}
\hline Usia & (n) & (\%) \\
\hline$\leq 20$ & 50 & 23,36 \\
$21-30$ & 61 & 28,51 \\
$31-40$ & 20 & 9,35 \\
$41-50$ & 29 & 13,55 \\
$51-60$ & 26 & 12,15 \\
$>60$ & 8 & 13,08 \\
Total & 214 & 100 \\
\hline
\end{tabular}

\section{BAHASAN}

Berdasarkan hasil penelitian diperoleh hasil responden yang menjalani perawatan gigi tiruan di tahun 2013 terbanyak berjenis kelamin perempuan $(61,15 \%)$ dan pada tahun 2014 persentase responden berjenis kelamin perempuan tetap mendominasi yakni sebanyak 68,22\%. Jika dilihat responden yang melakukan perawatan gigi tiruan di RSGM Prodi Pendidikan Dokter Gigi FK Unsrat umumnya merupakan pasien yang dibawa sendiri oleh mahasiswa profesi, bukan pasien yang berkunjung atas inisiatif sendiri.

Tabel 5. Distribusi responden gigi tiruan di RSGM berdasarkan jenis gigi tiruan tahun 2013.

\begin{tabular}{|c|c|c|}
\hline $\begin{array}{c}\text { Jenis gigi } \\
\text { tiruan }\end{array}$ & (n) & (\%) \\
\hline $\begin{array}{l}\text { Gigi tiruan } \\
\text { penuh }\end{array}$ & 5 & 3,60 \\
\hline $\begin{array}{l}\text { Gigi tiruan } \\
\text { sebagian } \\
\text { penuh }\end{array}$ & 9 & 6,47 \\
\hline $\begin{array}{l}\text { Mahkota } \\
\text { Pasak }\end{array}$ & 56 & 40,29 \\
\hline $\begin{array}{l}\text { Gigi tiruan } \\
\text { jembatan }\end{array}$ & 16 & 11,51 \\
\hline $\begin{array}{l}\text { Mahkota } \\
\text { penuh } \\
\text { Total }\end{array}$ & $\begin{array}{c}53 \\
139\end{array}$ & $\begin{array}{c}38,13 \\
100\end{array}$ \\
\hline
\end{tabular}

Tabel 6. Distribusi responden gigi tiruan di RSGM berdasarkan jenis gigi tiruan tahun 2014

\begin{tabular}{lcc}
\hline Jenis gigi tiruan & (n) & (\%) \\
\hline $\begin{array}{l}\text { Gigi tiruan } \\
\text { penuh }\end{array}$ & 41 & 19,16 \\
$\begin{array}{l}\text { Gigi tiruan } \\
\text { sebagian penuh }\end{array}$ & 36 & 16,82 \\
$\begin{array}{l}\text { Mahkota Pasak } \\
\text { Gigi tiruan }\end{array}$ & 36 & 16,82 \\
jembatan & 31 & 14,49 \\
$\begin{array}{l}\text { Mahkota penuh } \\
\text { Total }\end{array}$ & 70 & 32,71 \\
\hline
\end{tabular}

Menurut pendapat penulis, banyaknya 
pasien berjenis kelamin perempuan yang melakukan perawatan gigi tiruan antara lain disebabkan karena perempuan lebih mudah dimotivasi apabila perawatan yang dilakukan berkaitan dengan estetika pasien. Perempuan lebih mementingkan estetika dibandingkan laki-laki. Hal ini didukung oleh jenis perawatan yang banyak dilakukan baik di tahun 2013 maupun tahun 2014 berupa perawatan di gigi anterior. Jenis perawatan dimaksud yaitu perawatan mahkota pasak $(40,29 \%)$ dan mahkota penuh $(38,13 \%)$ di tahun 2013 serta perawatan mahkota penuh $(32,71 \%)$ dan perawatan mahkota pasak (16,82\%) di tahun 2014. Di samping lebih mementingkan estetika, perempuan lebih memilih gigi tiruan yang tidak dilepaslepas untuk memberikan kenyamanan dan menambah rasa percaya diri bagi pemakainya.

Perawatan gigi tiruan mahkota pasak merupakan perawatan lanjutan setelah pasien dilakukan perawatan saluran akar untuk mempertahankan gigi berlubang atau karies agar tidak diekstraksi. Dengan demikian perawatan mahkota pasak merupakan pilihan perawatan untuk mempertahankan estetika sekaligus agar gigi asli yang dipertahankan bisa difungsikan kembali. Demikan halnya dengan perawatan mahkota penuh yang memiliki nilai plus estetika yang relatif lebih baik dibandingkan tumpatan pada gigi dengan karies yang cukup besar atau karies pada beberapa lokasi di permukaan satu gigi. Banyaknya responden perempuan yang menjalani perawatan gigi tiruan juga dapat merupakan gambaran masalah gigi dan mulut yang dihadapi perempuan. Hingga saat ini masalah karies dan penyakit periodontal masih merupakan masalah yang mendominasi permasalahan kesehatan gigi dan mulut masyarakat. Penyakit karies dan penyakit periodontal antara lain merupakan penyebab hilangnya gigi seseorang. Menurut Cobert dkk (2001) menyatakan bahwa perempuan memiliki lebih besar resiko penyakit karies penyakit dibandingkan penyakit periodontal yang dapat menyebabkan hilangnya gigi.

Berdasarkan usia responden, sebagian besar perawatan gigi tiruan pada tahun 2013 dilakukan pada pasien dalam rentang usia 21-30 tahun (48,20\%), dan yang paling sedikit >60 tahun yang berjumlah 6 (4,32\%) orang. Hal yang sama terjadi pada perawatan gigi tiruan di tahun 2014. Responden pada rentang usia 21-30 tahun merupakan jumlah terbanyak yang melakukan perawatan gigi tiruan $(28,51 \%)$ orang, dan yang paling sedikit pasien usia $>60$ tahun yang berjumlah 8 $(13,08 \%)$ orang. Responden yang menjalani perawatan gigi tiruan lebih banyak pada pasien dalam rentang usia 2130 tahun. Hasil Riskesdas 2013 menunjukkan proporsi masyarakat dalam kelompok usia 25-34 tahun yang bermasalah dengan gigi dan mulutnya sebesar 28,5\%. Hasil ini tidak berbeda jauh dengan proporsi terbesar (31,9\%) pada kelompok usia 35-44 tahun. Kelompok usia 21-30 tahun masih tergolong usia dewasa muda, dimana pada wanita yang sudah menikah dan mengalami kehamilan akan merupakan usia rentan bagi terjadinya karies dan penyakit periodontal. Pada kehamilan akan terjadi ketidakseimbangan hormonal yang bisa berpengaruh pada kondisi jaringan periodontal. Di samping itu wanita hamil rentan terhadap karies akibat pengaruh kehamilan. Keadaan ini bisa merupakan penyebab terjadinya kehilangan gigi pada wanita hamil serta mendorong pasien atau penderita untuk menggunakan gigi tiruan. Menurut Ariyani, karies dan penyakit periodontal menjadi penyebab umum kehilangan gigi. $^{10,12}$

Usia seseorang merupakan salah satu ciri kedewasaan fisik dan kematangan psikologis yang berkaitan dalam memberikan tanggapan atau respon terhadap objek yang di sekitarnya. Usia yang semakin dewasa akan lebih mudah memberikan tanggapan yang diperoleh baik melalui pendidikan maupun 
pengalaman-pengalaman lain. ${ }^{19}$ Adanya dorongan atau motivasi yang diberikan oleh mahasiswa profesi yang didesak oleh kebutuhan mereka akan pasien, di antaranya pasien perawatan gigi tiruan; turut mendorong masyarakat termasuk para perempuan untuk mau menjalani perawatan gigi tiruan guna mengganti gigi yang hilang atau memperbaiki gigi yang rusak serta melanjutkan perawatan yang sudah dilakukan.

Pada tahun 2013 jenis perawatan gigi tiruan yang paling banyak dilakukan responden yakni perawatan gigi tiruan mahkota pasak pada 56 responden $(40,29 \%)$ dan yang paling sedikit perawatan gigi tiruan penuh pada 5 responden (3,60\%) dan pada tahun 2014 responden yang menjalani perawatan mahkota penuh sebanyak 70 orang (32,71\%) dan yang paling sedikit perawatan gigi tiruan jembatan yang berjumlah 31 (14,49\%) orang. Hal ini mungkin disebabkan karena perawatan mahkota pasak yang dilakukan sebagian besar dilakukan pada gigi anterior, demikian halnya dengan perawatan mahkota penuh atau mahkota jaket. Kerusakan pada gigi anterior yang dapat merupakan indikasi untuk perawatan gigi tiruan mahkota pasak serta mahkota penuh berhubungan dengan estetik pasien, sehingga responden merasa perlu untuk segera mengganti atau merawat giginya karena dapat memengaruhi estetik dan menganggu penampilan secara fisik. Menurut Bedi R dan McGranth, kehilangan atau kerusakan gigi dapat memengaruhi fisik seperti estetik, selain sistem mastikasi dan kenyamanan berbicara. ${ }^{22,23}$ Sedikitnya kasus gigi tiruan penuh pada perawatan tahun 2013, mungkin disebabkan karena kasus gigi tiruan penuh merupakan kasus yang sulit untuk dilakukan. Berdasarkan tanya jawab yang penulis lakukan dengan beberapa mahasiswa profesi yang melayani pasien di RSGM, ternyata pasien perawatan gigi tiruan penuh termasuk kasus yang sulit dicari. Sering terjadi mahasiswa membawa pasien untuk diajukan sebagai pasien perawatan gigi tiruan penuh, namun oleh karena alasan kondisi mulut pasien yang tidak mendukung dan dapat menyulitkan mahasiwa, maka pasien yang sudah ada tidak bisa dikerjakan oleh mahasiswa. Keadaan ini bisa merupakan penyebab kurangnya perawatan gigi tiruan penuh di tahun 2013.

Hasil penelitian tahun 2014 berkaitan dengan jumlah perawatan gigi tiruan yang dilakukan pada pasien yang berkunjung ke RSGM Prodi Pendidikan Dokter Gigi FK Unsrat lebih banyak merupakan perawatan mahkota penuh. Hal ini dikarenakan beberapa alasan yaitu masyarakat merasakan gigi tiruan mahkota penuh lebih dibutuhkan karena faktor estetik. Selain itu kasus perawatan gigi tiruan mahkota penuh berupa mahkota jaket lebih mudah didapatkan dibandingkan kasus gigi tiruan lepasan sesuai kriteria yang ditentukan dari program studi.

\section{SIMPULAN}

Berdasarkan hasil penelitian yang dilakukan, diperoleh dua kesimpulan yakni Tahun 2013 perawatan terbanyak mahkota pasak 40,29\%, diikuti mahkota penuh 38,13\%; gigi tiruan jembatan $11,51 \%$; gigi tiruan lepasan $6,47 \%$; gigi tiruan penuh 3,60\%. Tahun 2014 perawatan terbanyak perawatan mahkota penuh $32,71 \%$, diikuti gigi tiruan penuh 19,16\%; gigi tiruan sebagian lepasan $16,82 \%$; mahkota pasak 16,82\%; gigi tiruan jembatan 14,49\%.

\section{SARAN}

Disarankan hasil ini penelitian dapat dimanfaatkan oleh pihak RSGM berkoordinasi dengan program studi untuk digunakan dalam perencanaan kebutuhan bahan dan obat di Rumah Sakit Gigi dan Mulut Program Studi Pendidikan Dokter Gigi FK Unsrat. Hasil penelitian ini juga dapat merupakan informasi yang dapat dimanfaatkan oleh Program Studi Pendidikan Dokter Gigi FK Unsrat dalam melakukan pembenahan. 
DAFTAR PUSTAKA

1. Jubhari EH. Thinking pattern of first grade students towards edentulous replacement. Dent J (Maj Ked Gigi) $2007 ; 40: 65-9$

2. Jubhari EH. Alasan mahasiswa fakultas kedokteran gigi tidak menggunakan gigi tiruan. Dentofasial. 2008; 7 (2); 124-131

3. Riset Kesehatan Dasar (RISKESDAS). [serial online] 2007; [dikutip pada 31 juli 2015]. Available from: URL:http:/download.portalgaruda.or g/article.php?article $=107415 \& v a l=1$ 000

4. Cary NC. Affordable custom dentures partials, complete. [internet]. North Caroline: Academy of General Dentistry; 2012 [cited 2011 Nov 13]. Available from http://www.drashleymann.com/dentu res.html.

5. Hermina P. Alasan masyarakat kelurahan Sario Tumpaan tidak menggunakan gigitiruan. [Serial online]. 2013. Tersedia dari: URL: http://download.portalgaruda.org/arti cle.php?article $=107415 \& v a l=1000$

6. Notoatmodjo S. Promosi kesehatan dan ilmu perilaku. Jakarta: Rineka Cipta; 2007

7. Loney RW. Removable partial denture manual. [Serial Online]. 2011. Tersedia dari: URL: http://www.scribd.com/doc/9413346 2

8. Tarigan, Slamet, 2005. Pasien prostodonsia lanjut usia : Beberapa pertimbangan dalam perawatan. [cited 30 juni 2015]; Available from URL:www.usu.ac.id/id/files/pidato/p pgb/2005/ppgb-2005-slamettarigan.pdf

9. Hamsafir E. Gigi palsu dalam dunia kedokteran gigi. [internet]. 2011 [dikutippada 7 juli 2015]. Tersedia dari: http://www.infogigi.com/575/gigipalsu-dalam-dunia-kedokterangigi.html

10.Peranci A. Behaviour and hyiene habits of completedenture wearers. Braz Dent J 2010; 21(3): 247-52.

11.Phoenix RD, Cagna DR. Stewart's. Clinical removable partial prostodonics. 3th ed. Chicago. 2003; p. 1-3, 6-8. 